\title{
CATULO REVISITADO: REFLEXÕES SOBRE PROPOSTAS DE TRADUÇÕES DO POEMA 16 EM LÍNGUA PORTUGUESA
}

\author{
Diogo Martins Alves \\ Universidade Estadual de Campinas \\ Campinas. Campinas, São Paulo, Brasil
}

\begin{abstract}
Resumo: Gaio Valério Catulo (87-84 e 57-54 a.C.) é, para os modernos, o principal representante da corrente estética em que sua poesia se insere, o chamado "neoterismo". Também é considerado um dos poetas latinos mais traduzidos da Antiguidade (Vasconcellos, 1991, p. 11). Paradoxalmente, a transmissão de seu libellus sofreu diversas interpolações ao longo do tempo, sobretudo em relação aos poemas que contêm determinado léxico sexual. No presente estudo, apresentamos um breve panorama sobre o modo como editores e tradutores portugueses lidaram com o texto latino de Catulo, mais especificamente, com relação ao carmen 16. Nesse poema, Catulo emprega, no primeiro e último versos, termos de cunho sexual, a saber: os verbos pedicabo e irrumabo, que denominam o ato de penetrar por via anal e oral, respectivamente. A presença desses vocábulos fez com que editores do texto latino em alguma medida censurassem sua divulgação. Desse modo, nosso objetivo se divide em duas etapas: i) observar como editores dos textos latinos têm lidado com esse texto, e ii) analisar as escolhas tradutórias no poema vertido para a língua portuguesa, de maneira a refletir sobre como a supressão ou atenuação de um vocabulário obsceno vem sendo reconsideradas, sobretudo em traduções brasileiras.
\end{abstract}

Palavras-chave: Letras Clássicas; Catulo; Obscenidade; Tradução; Censura 


\title{
CATULLUS REVISITED: CONSIDERATIONS ON TRANSLATION PROPOSALS OF THE 16 POEM IN PORTUGUESE
}

\begin{abstract}
Gaius Valerius Catullus (87-84 and 57-54 b.C.) is the main representative of the aesthetic trend in which his poetry is inserted, the so-called "neoterismo". Also, he is considered one of the most translated Latin poets of antiquity (Vasconcellos, 1991, p. 11). Paradoxically, the transmission of his libellus has undergone several interpolations, especially in relation to the poems that contain certain sexual lexicon. In this study, we present a brief overview of how editors and Portuguese translators have dealt with the Latin text of Catullus, specifically with regard to the carmen 16 . In this poem, Catullus uses, in the first and last verses, terms of a sexual nature, namely the verbs pedicabo and irrumabo, which denominate the anal and oral penetration act, respectively. The presence of these words led the Latin text editors to censure its disclosure. Thus, our goal is twofold: i) to observe how editors of the Latin text have dealt with this poem, and ii) to analyse the translation choices in Portuguese versions, in order to reflect on how suppression or attenuation of obscene vocabulary have been reconsidered, especially in Brazilian translations.
\end{abstract}

Keywords: Classical letters; Catullus; Obscenity; Translation; Censorship

\section{Introdução}

Gaio Valério Catulo viveu entre os anos 87-84 e 57-54 a.C., e sua obra é hoje a maior representante da estética neotérica que nos foi legada, cujos adeptos foram denominados por Cícero (Orat. 161) como poetae noui, expressão pejorativa que remete ao fato de que esses poemas romperam com uma tradição antiga, de epos de tipo homérico e eniano, que versava sobre as proezas de seus antepassados. ${ }^{1}$ Assim, Catulo passou a promover a poesia de circunstância (nugae), em que qualquer matéria poderia ser elaborada,

${ }^{1}$ Em grego, chamados de neoteroi, "neotéricos": alusão ao movimento literário de poetas gregos no período helenístico, sobre o qual discorreremos adiante.

Cad. Trad., Florianópolis, v. 38, n $^{0}$ 2, p. 120-142, mai-ago, 2018 
transformada, tendo por finalidade o prazer estético (VASCONCELLOS, 1991, p. 18). ${ }^{2}$

Esse tipo de fazer poético foi praticado não apenas por Catulo como também por um grupo de poetas coevos. No entanto, apenas a obra de Catulo nos foi legada, e as informações a que temos acesso sobre os demais poetas se dão por meio de testemunhos indiretos. ${ }^{3}$ Sobre o poeta Catulo mesmo, há poucas informações, o que contribui, como veremos adiante, para a forma biografista como sua poesia tem sido interpretada não apenas pelos críticos posteriores, mas também por alguns de seus contemporâneos. O que se sabe, concretamente, é que o poeta, proveniente de uma família abastada, nasceu em Verona e ainda bastante jovem se mudou para Roma. Mais tarde, integrou a comitiva do pretor Caio Mêmio e foi enviado numa expedição militar à Bitínia, região que hoje compreende a atual Turquia (OLIVA NETO, 1996, p. 16). ${ }^{4}$

Compreender a poesia catuliana se faz relevante sobretudo porque sua estética influenciou a recepção da sua obra ao longo dos séculos. Nossa intenção, no presente estudo, é mostrar como determinada moral influenciou na recepção do texto latino e em que medida os editores procuraram censurá-lo, seja por meio da interpolação de versos, seja pela omissão de poemas inteiros, e em que medida essa mesma concepção também influenciou nas traduções dos poemas em língua portuguesa, mais especificamente, as do poema 16 .

A seguir, procuraremos apresentar o livro de Catulo que nos foi legado.

\footnotetext{
${ }^{2}$ Sobre a poesia de circunstância e a influência helenística nas composições de Catulo, indicamos a leitura dos textos introdutórios das edições de Fordyce (1987) e de Thomson (1997), além das introduções das traduções brasileiras de Vasconcellos (1991) e Oliva Neto (1996).

${ }^{3}$ Uma apresentação sobre os neotéricos mencionados no livro de Catulo discutimos em Alves (2009, p. 24-35). Cf. também Gallardo (1990, p. 19-30).

${ }^{4}$ Uma apresentação mais detalhada sobre a vida e obra de Catulo discutimos em Alves et al. (2008, p. 451-459).
} 


\section{A poesia neotérica e o livro de Catulo}

A obra do poeta veronense ultrapassa o número de cem poemas, e é comumente dividida em três partes: os 60 primeiros poemas são considerados poesia de circunstância, versados em metros variados; os poemas 61 a 68, também em metros variados, são de maior extensão (chegando a mais de quatrocentos versos), e são denominados carmina docta ou carmina longiora ("poemas eruditos" ou "poemas mais longos", respectivamente); por fim, os demais poemas são em sua maioria epigramas, em dísticos elegíacos, que versam sobre Lésbia e Juvêncio, amados de Catulo, além de invectivas contra seus rivais, entre outros temas (Vasconcellos, 1991, p. 19; Oliva Neto, 1996, p. 35). É importante ressaltar que essa composição do livro, como a que temos acesso atualmente, não é consenso entre os estudiosos. Isso porque, segundo eles, os poemas maiores não se encaixariam no conceito de nugae, como o próprio Catulo menciona no poema de abertura de seu livro. ${ }^{5}$

Para compreender a poesia de Catulo, é necessário atentar para o que foi a poesia neotérica na Grécia, e em que medida séculos depois ela influenciou os poetas romanos. Um dos principais expoentes dessa corrente foi Calímaco de Cirene (310 a.C. - 240 a.C.), poeta sobre o qual pouco se sabe, mas de grande influência para os poetas novos, visto que foi não apenas imitado como também mencionado pelo próprio Catulo em dois de seus poemas, a saber: os poemas 65 e 116, assim como o poema 66 é uma tradução de sua elegia “A Trança de Berenice” (OLIVA NETO, 1996, p. 63). ${ }^{6}$

A poesia de Calímaco rechaçava poemas épicos longos e cíclicos, que narravam as façanhas de deuses e heróis. Esse fazer poético do período helenístico chegou aos romanos via Partênio

\footnotetext{
${ }_{5}^{5}$ Cf. Oliva Neto (1996, p. 57): Quoi dono lepidum noum libellum/ arida modo pumice expolitum?/ Corneli, tibi, namque tu solebas/ meas esse alicquid putare nugas "A quem dedico esta graça de livro/ novinho em folhas recém-buriladas?/ A ti, Cornélio, pois tu costumavas/ Ver uma coisa qualquer nestas nugas" (Carm. 1, vv. 1-4, tradução de João Ângelo Oliva Neto).

${ }^{6}$ Sobre as obras de Calímaco, cf. Mair (1989); Kenney and Clausen (1996, p. 815-816).
} 
de Nicéia, poeta grego capturado e levado para Roma no ano de 73 a.C., e que teria então difundido ali a obra calimaquiana. Sob essa influência, Catulo e seus coevos protagonizaram importantes transformações no cenário da poesia romana, de modo que seus poemas, diferentemente das longas narrativas épicas, eram menores e assumiram uma perspectiva mais subjetiva. ${ }^{7}$

Além de produzir uma literatura distinta da então propagada em Roma, Catulo atribuiu seu próprio nome à sua persona. Associado às características subjetivas dessa nova poesia romana, esse recurso fez com que sua poesia passasse a ser interpretada de modo biografista, como se as menções à persona Catulo fossem ao próprio poeta empírico. Tal recepção de sua poesia foi inclusive tema do poema ao qual pretendemos nos ater no presente estudo: o carmen 16.

\section{Carmen 16 de Catulo: recepção e transmissão}

Como mencionamos anteriormente, a atividade poética de $\mathrm{Ca}$ tulo visava a transformação de qualquer matéria, de temática banal e cotidiana, em poesia, buscando atingir um grau de elaboração e refinamento até então inéditos na literatura latina (VASCONCELLOS, 1991, p. 18). O carmen 16, versado em hendecassílabos, é direcionado a dois contemporâneos de Catulo, Aurélio e Fúrio. O motivo da invectiva, como veremos a seguir, seria a interpretação biográfica que eles teriam feito dos poemas de Catulo, de modo a questionar sua virilidade. ${ }^{8}$ Atentar para a recepção da obra se faz necessário para compreendermos em que medida os recursos empregados por Catulo influenciaram a transmissão de sua obra,

\footnotetext{
${ }^{7}$ A importância dessa assimilação é apontada por Oliva Neto, uma vez que a poesia helenística já existia desde o século III a.C., mas foram os poetas do grupo de Catulo que "incluíram a poesia latina na literatura mais sofisticada do período, que era escrita em grego". Cf. Oliva Neto (1996, p. 16).

${ }^{8}$ Alguns estudiosos divergem sobre quais poemas teriam recebido tal interpretação, se os dedicados a Lésbia ou a Juvêncio. O estudo mais recente a que tivemos acesso é o de Vasconcellos (2015), que procura demonstrar, por meio de análise intratextual, tratar-se do carmen 5, dedicado a Lésbia.
} 
sobretudo nas traduções em língua portuguesa, foco de nosso presente estudo.

A seguir, apresentamos o poema na tradução de João Ângelo Oliva Neto, publicada no ano de 1996, pela editora Edusp:

Pedicabo ego uos et irrumabo, Aureli pathice et cinaede Furi, qui me ex uersiculis meis putastis, quod sunt molliculi, parum pudicum. nam castum esse decet pium poetam ipsum, uersiculos nihil necesse est, qui tum denique habent salem ac leporem, si sunt molliculi ac parum pudici et quod pruriat incitare possunt, non dico pueris, sed his pilosis qui duros nequeunt mouere lumbos. Vos, quei milia multa basiorum legistis, male me marem putatis? Pedicabo ego uos et irrumabo.

Meu pau no cu, na boca, eu vou meter-vos, Aurélio bicha e Fúrio chupador, que por meus versos breves, delicados, me julgastes não ter nenhum pudor. A um poeta pio convém ser casto ele mesmo, aos seus versos não há lei. Estes só têm sabor e graça quando são delicados, sem nenhum pudor, e quando incitam o que excite não digo os meninos, mas esses peludos 10 que jogo de cintura já não têm. E vós, que muitos beijos (aos milhares!) já lestes, me julgais não ser viril? Meu pau no cu, na boca, eu vou meter-vos. 
A fim de compreender o poema, faz-se necessário contextualizar sobre a sociedade romana dessa época. Embora a relação homossexual fizesse parte das relações sociais nesse período em Roma, havia determinados códigos que deveriam ser seguidos pelos cidadãos romanos (OLIVA NETO, 1996, p. 49). E é exatamente a esses códigos que Catulo faz alusão nos versos 1 e 14: a relação sexual por via anal e oral, presentes nos verbos pedicabo e irrumabo, respectivamente. Sabe-se que a um cidadão romano dessa época não convinha praticar a felação, tampouco ser passivo em uma relação anal, uma vez que isso feriria a sua uirtus. Tais atividades eram praticadas por aqueles com estatuto inferior, como mulheres e escravos.

Por meio do emprego desses termos, Catulo acusa Aurélio e Fúrio por terem questionado sua virilidade, na condição de poeta empírico, por ele ter escrito poemas de cunho amoroso considerados efeminados (VASCONCELLOS, 2012, p. 90). Um dos recursos que destaca a agressividade presente no poema é o fato de Catulo atribuir seu nome à sua persona poética (OLIVA NETO, 1996, p. 36). Tal artifício também influenciou a recepção da obra ao longo do tempo: estudiosos posteriores acabaram por realizar uma leitura biográfica da obra, já que uma das justificativas para excluir o poema 16 da coletânea de texto de Catulo era a de que um poeta como Catulo, notório por seus versos amorosos, jamais escreveria um poema tão pornográfico (SISSON apud WINTER, 1973, p. 259-260).

Além disso, estudos recentes revelam que os artifícios empregados por Catulo não se limitam apenas à sua persona, mas também a de seus interlocutores. Segundo Oliva Neto, a alusão aos indivíduos interpelados nos poemas de Catulo ganha estatuto de metapoesia, uma vez que eles representam, antes que indivíduos empíricos, um conjunto de ideias presentes em uma sociedade. Desse modo, ao abordar o fazer poético, esse recurso acaba por atribuir ao poema determinada proximidade e verossimilhança, que, aliadas aos tópicos da poesia de circunstâncias, "faz parecer espontâneo e emotivo 
o que também é construção" ${ }^{9}$ E é a essa construção que poderíamos atribuir a recepção negativa e, em certa medida, factual dos poemas de Catulo que, consequentemente, resultaria na censura a que sua obra foi submetida.

De acordo com Oliva Neto, Catulo foi redescoberto no Renascimento, e foi por meio da tradução que sua obra ganhou notoriedade (OLIVA NETO, 1996, p. 52). Entretanto, no que se refere aos poemas obscenos, demorou alguns séculos para que sua obra recebesse um tratamento honesto. ${ }^{10}$ Nas palavras de C. H. Sisson, "a obscenidade de Catulo tem sido um obstáculo", ${ }^{11}$ que nem sempre foi enfrentado pelos seus editores e tradutores. ${ }^{12}$ Isso porque algumas edições dos textos latinos receberam diversas interpolações sob o argumento de que esses poemas não eram adequados a um autor como Catulo, ou então que eles apenas não mereceriam comentário algum.

Um exemplo desse tipo de procedimento é possível encontrar na edição de F. W. Cornish, datada de 1913. Publicada pela coleção Loeb Classical Library, em latim e inglês, nessa edição os versos obscenos do poema 16 de Catulo foram substituídos por asteriscos. Além disso, o poema mesmo não foi publicado em sua totalidade,

\footnotetext{
${ }^{9}$ Esse recurso se insere no gênero filosófico diatribe estóico-cínica, que emprega exemplos, citações e introduz interlocutores a fim de desenvolver uma discussão. Cf. Oliva Neto (1996, p. 45-46).

${ }^{10}$ Empregamos aqui obscenidade para designar um tipo de linguagem que cria certo desconforto no leitor ao descrever atos sexuais, mais especificamente, aqueles que em alguma medida violam padrões estabelecidos em uma sociedade. No caso do poema 16 , com uma função bastante específica: a de agressão e de humilhação de seus interlocutores. Cf. Adams (1982, p. 1-6). Sobre a obscenidade em Catulo, suas variações e efeitos, cf. Lateiner (2007, 261-282).

11 "The obscenity of Catullus has long been a stumbling block", Sisson apud Winter (1973, p. 257). No entanto, como veremos adiante, o próprio Sisson endossa determinada censura ao poema 16 .

${ }^{12}$ Um estudo aprofundado sobre propostas de traduções de textos obscenos para o inglês, tanto gregos quanto latinos, é discutido por Roberts (2008, p. 278-313). Nesse trabalho, o estudioso procura analisar traduções publicadas entre os anos de 1800 e 1950, abordando questões como a fronteira entre o clássico (tido como elevado) e o obsceno (considerado baixo, vil), destacando o posicionamento do tradutor e sua relação com o leitor. Sobre as propostas de traduções dos poemas de Catulo para o inglês publicadas a partir de 1961, cf. o recente estudo de Lee (2016), que procura analisar versões dos poemas 16, 37 e 97.
} 
tendo sido eliminados seus oitos últimos versos, estando ausente qualquer nota explicativa sobre essa ação, de modo que o leitor não especialista que se depara com o poema, nessas condições, acaba por acreditar ser esse o poema de Catulo em sua totalidade. ${ }^{13}$ Essa ação, além de comprometer o acesso ao texto em língua latina, também prejudica sua difusão em outros idiomas, uma vez que o tradutor, que toma essa edição inglesa como original, ao se deparar com esse poema sem aparato crítico, acaba por vertê-lo em outra língua sem comunicar seu leitor sobre a intervenção.

De maneira ainda mais severa foi o tratamento dado à edição de C. J. Fordyce, datada de 1961. Publicada pela editora Oxford, nesse caso seu editor simplesmente expurgou os poemas obscenos da obra, fazendo uma breve menção a isso em seu texto introdutório: "Alguns poemas que não se prestam a comentar em inglês foram omitidos" ${ }^{14}$ Novamente, deparamo-nos com uma ação que interfere significativamente na difusão da obra. Essa prática parece demonstrar que determinada tradição exegética visou construir a imagem de um Catulo isento de qualquer traço obsceno. Ou, como sugere Winter, "um fino cavaleiro vitoriano sem interesses lascivos". ${ }^{15}$

Esse tipo de tratamento com o texto de Catulo não se limitou apenas a omitir versos em latim ou a expurgar poemas inteiros, mas

\footnotetext{
${ }^{13}$ Cf. Winter (1973, p. 259). É interessante observar que o mesmo C. H. Sisson, que assume a dificuldade de se trabalhar com os poemas, concorda com essa intervenção, como nos informa Winter (1973, p. 259-260). Em sua edição do livro de Catulo, em latim e inglês, publicada no ano de 1967 pela editora The Orion Press, Sisson afirma: "Parece-me que o poema está melhor sem as últimas oito linhas. Na versão mais curta, Catulo está fazendo uma asserção (como sempre): as linhas adicionais provavelmente são espúrias. Não é do feitio de Catulo exaltar a qualidade pornográfica do que escreveu; sua mente estava muito mais em seu tema" ("it seems to me that the poem is better without them the last eight lines. In the shorter version, Catullus is making a point (as always): the additional lines are probably spurious. It is unlike Catullus to exalt the pornographic quality of what he wrote; his mind was too much on his subject").

14 "A few poems which do not lend themselves to comment in English have been omitted", cf. Fordyce (apud WINTER, 1973, p. 258); Vasconcellos (2015, p. 59 n. 7); Trimble (2012; p. 143). De acordo com Fitzgerald (1995, p. 60), foram expurgados da edição de Fordyce um total de 32 poemas de Catulo. Cf. também Lee (2016, p. 10).

15 "A fine Victorian gentleman without prurient interests", cf. Winter (1976, p. 260). Sobre o expurgo de poemas obscenos de Catulo das edições latinas comentadas, publicadas até o ano de 1961, cf. Trimble (2012, p. 143-162).
} 
também se fez presente nas traduções. Se em algumas delas os versos obscenos não eram vertidos, em outras a versão apresentada era bastante atenuada e distinta do sentido latino. E não foi diferente com algumas traduções em língua portuguesa, como veremos a seguir.

\section{AS TRADUÇÕES PORTUGUESAS: EUFEMISMO, CENSURA E RECONHECIMENTO}

Assim como as edições inglesas, as traduções da obra de Catulo também sofreram intervenções em suas versões para a língua portuguesa, a começar pelo fato de que muitas não apresentam uma versão completa da obra, mas apenas alguns poemas selecionados. Essa seleção já nos diz muito sobre o modo como os tradutores enxergam Catulo: em sua maioria, os poemas selecionados são os que apresentam temas amorosos, sobretudo os dedicados à Lésbia. Parece-nos que a influência do romantismo, com seu viés biográfico, contribuiu sobremaneira com esse tipo de recepção. ${ }^{16}$

Das traduções poéticas, como nos informa Oliva Neto, as primeiras surgiram no século XIX: as de Almeida Garrett (17991854); as de António Feliciano de Castilho (1800-1875); as de Aires de Gouveia (1828-1926); as de Lucindo Filho (1847-1896); e as de Francisco Otaviano (1825-1899). ${ }^{17}$ A primeira tradução comple-

\footnotetext{
${ }^{16}$ Sobre essa questão, seria inocência creditar apenas à influência pós-romântica essa leitura biográfica do texto de Catulo, assim como aponta Vasconcellos (2016, p. 52). Sobretudo porque o próprio poema que aqui estudamos, datado do século I a.C., versa sobre esse tipo de leitura. Entretanto, o que pretendemos destacar é que esse tipo de leitura parece querer negar a atribuição de algum traço de obscenidade a Catulo, na condição de poeta empírico, de tal modo que isso refletiu nas escolhas dos tradutores em suas propostas de traduções dos poemas, sobretudo o poema 16. Associado a tal imaginário, parece-nos também que o uso político que era feito do latim contribuiu para essa forma de recepção. Sobre essa questão, trataremos adiante. Ainda sobre a distinção entre autor empírico e persona poética, mas em testemunhos antigos, cf. um levantamento recente e detalhado realizado por Vasconcellos (2016, p. 11-52).

${ }^{17}$ Cf. Oliva Neto (1996, p. 53), que, por sua vez, baseia-se na obra A tradição clássica na literatura portuguesa, de Luís de Souza Rebelo. Há também, como nos informa Oliva Neto, diversas antologias quem contêm traduções de alguns poemas de Catulo. No entanto, apenas duas delas apresentam uma tradução do poema 16 , como veremos adiante.
}

Cad. Trad., Florianópolis, v. 38, $\mathrm{n}^{0}$ 2, p. 120-142, mai-ago, 2018 
ta da obra de Catulo para a língua portuguesa surgiu em 1933, em Coimbra, e é a essa versão que nos deteremos agora.

Agostinho da Silva, filólogo português que viveu entre 1906 e 1994, publicou em Coimbra, pela editora Imprensa da Universidade, uma tradução completa da obra de Catulo, em prosa, em uma edição bilíngue, com estudo introdutório e aparato crítico. No entanto, é interessante observar que, apesar de todo o cuidado para com o texto latino, essa edição não se eximiu de interferir claramente no poema, como vemos a seguir:

Eu vos mostrarei a minha virilidade, obsceno Aurélio e crapuloso Fúrio, que, pelos meus versos galantes, me julgastes devasso. Deve ser o bom poeta virtuoso em si e não é necessário que o seja nos seus versos; estes mais graça e elegância terão se forem voluptuosos e pouco pudicos e se excitarem o desejo, não digo aos rapazes, mas aos peludos que já não podem mover os rins entorpecidos. Vós julgaisme efeminado porque lestes «muitos milhares de beijos»? Eu vos mostrarei a minha virilidade.

A tradução proposta por Agostinho da Silva para o verso pedicabo ego uos et irrumabo é bastante distinta do sentido presente no texto latino. Ao optar por "eu vos mostrarei a minha virilidade", notamos que ao leitor que desconhece a língua latina não é possível cotejar a tradução com o texto latino e perceber a omissão realizada pelo tradutor. Além disso, podemos notar que o termo "virilidade" está muito aquém de representar as relações sexuais a que Catulo subjuga seus rivais. Poderíamos, inclusive, sugerir que, devido ao apagamento realizado por Agostinho da Silva, sua proposta de tradução, eufemística, tampouco se enquadraria no conceito de texto obsceno, tal qual o definimos anteriormente.

Um segundo estranhamento surge com a tradução de Agostinho da Silva. Trata-se da nota de rodapé que segue ao primeiro verso do poema 16: "tradução muito atenuada do texto". Indicaria tal nota algum comprometimento com o leitor, ou seria apenas um 
recurso do tradutor a fim de não se comprometer ao traduzir um poema obsceno? Novamente, apenas a afirmação de que se trata de uma versão atenuada não apresenta recursos suficientes que auxiliem o leitor a compreender o sentido que lemos no original do poema. Desse modo, lançar mão de tal nota parece apenas nos indicar mais uma declarada censura ao poema latino.

Trinta e oito anos depois, em 1971, uma outra tradução do poema, agora em versos, apresenta uma nova forma de censura. Em sua publicação pela editora Fora do Texto, o poeta e crítico português Jorge de Sena (1919-1978) mantém o primeiro e último versos em latim, entre aspas: ${ }^{18}$

"Pedicabo ego vos et irrumabo",

Aurélio sem dentes, Fúrio sem fundo,

Que de mim dizeis, porque são meus versos

Tão livres assim, que sou depravado.

Casto consigo deve ser o poeta,

Mas nada obriga a que a poesia o seja.

Licença e desvergonha são o sal

Com que versos se fazem. Assim excitem,

Senão crianças, ao menos os pilosos

Que enferrujados já não movem lombos.

E vós, porque de muitos mil de beijos

Lestes, que não sou macho andais dizendo?

"Pedicabo ego vos et irrumabo".

Sem nenhuma nota explicativa presente na tradução, o leitor que se depara com o poema, caso não detenha conhecimento suficiente em língua latina, não compreenderá o jogo construído por Catulo. Esse tipo de censura nos parece ainda mais grave que aquele aplicado por Agostinho da Silva, uma vez que, mantidos os versos em latim, o sentido do poema perde-se quase que por completo.

${ }^{18}$ Essa tradução compõe uma antologia, em dois volumes, de poemas traduzidos por Jorge de Sena. Em 1993, uma nova edição é publicada, agora em volume único. Nela, a tradução do poema 16 mantém os versos em latim. 
Chamamos a atenção, no entanto, para um fato curioso: no ano de $1975^{19}$, a tradução de J. Lourenço de Carvalho procura manter um sentido bem próximo ao do original latino:
Ó Aurélio brochista, ó Fúrio paneleiro, a vós que, sendo meus leves versos voluptuosos, por eles devasso me julgastes, eu vos hei-de enrabar e embrochar.
Ora se um autêntico poeta casto deve ser, não é força que seus versos o sejam.
Estes afinal sabor e encanto hão-de ter, se forem galantes e nada cândidos, e capazes de aguilhoar desejos, não digo nos moços, mas nesses pilosos que não podem já os engrunhidos rins mover. Vós, lá porque lestes muitos milhares de beijos, acaso me considerais falto de virilidade?
Pois hei-de vos enrabar e embrochar.

No entanto, podemos observar que essa tradução altera a ordem dos versos latinos, e evita iniciar o poema com o verso em que há os termos obscenos. Essa alteração, inclusive, compromete uma possível interpretação para o poema: segundo Krostenko (apud VASCONCELLOS, 2015, p. 63), a repetição do primeiro verso faz com que se crie um efeito de composição em anel. De acordo com o estudioso, em um primeiro momento o verso parece ser uma imprecação idiomática, porém ao longo do poema é construída a imagem do poeta como viril. Ao final, a partir da repetição Aurélio e Fúrio percebem que o sentido do primeiro verso é outro, e foram induzidos a interpretá-lo de maneira equivocada, da mesma forma como teriam lido os demais poemas de Catulo. Ainda assim, parece-nos ser essa a primeira proposta de tradução publicada em

${ }^{19}$ Essa tradução compõe uma antologia publicada pela Edições Afrodite. Embora se trate de uma antologia, não encontramos referência alguma de que essa tradução tenha sido publicada em alguma outra obra anterior ao ano de 1975. 
língua portuguesa que procura se aproximar ao sentido do conteúdo obsceno presente no poema de Catulo.

Interessante observar que, apenas quatro anos após a publicação de Sena, surge essa proposta de Lourenço de Carvalho, já livre de determinado julgamento de valor. Embora não tenhamos acesso ao contexto de produção da tradução de Jorge de Sena, no sentido de especular o público leitor a que se destinava essa tradução, parece-nos possível sugerir que ela ainda esteve associada ao tipo de recepção presente nas edições latinas do século $\mathrm{XX}$, que visava, quando não expurgar, ao menos silenciar de alguma forma tais versos obscenos.

Ao observarmos essas propostas de traduções que, em alguma medida, censuram o texto latino, outra questão possivelmente relacionada a tais atos merece ser destacada: a do uso político a que o latim esteve comumente submetido. ${ }^{20}$ Sabe-se que, durante muito tempo, o ensino de latim exercia uma função bastante marcada, na medida em que, além de ser visto como um instrumento de aprendizado da língua portuguesa era tido também como uma atividade disciplinadora, ligada a questões de educação moral e cívica, sobretudo quando associadas a uma visão conservadora e religiosa. ${ }^{21}$

Nesse sentido, diversos outros argumentos eram empregados para justificar o ensino do latim, como os de ampliação de vocabulário, maior conhecimento da gramática da língua portuguesa, capacidade de aguçar o intelecto, ampliar a capacidade de obser-

\footnotetext{
${ }^{20}$ Agrademos ao Prof. Dr. Guilherme Gontijo Flores pela observação acerca da representação do uso político do latim, durante nossa comunicação no XII Encontro Nacional de Tradutores e VI Encontro Internacional de Tradutores, na Universidade Federal de Uberlândia, em setembro de 2016.

${ }^{21}$ Esse posicionamento pode ser encontrado, inclusive, em introduções de gramáticas latinas publicadas no Brasil, como nos aponta Vasconcellos (2007, p. 113), que menciona, por exemplo, a edição de Rubens dos Santos, de 1987: “[o ensino do latim] abre caminhos para importantes domínios do mundo espiritual e social, desperta a consciência histórica, facilita a orientação na atualidade, incrementa o pensar autônomo criador e contribui para o desabrochar das forças próprias do homem". Ou ainda, a edição de Damião Berge, de 1985 (23 a edição): "Em nossos labores, consola-nos a certeza de termos cooperado para o florescimento da civilização românica entre nós, de termos provado nosso grande amor à Igreja e à Pátria, de termos, enfim, contribuído para o engrandecimento moral do Brasil e para a exaltação da Santa Igreja de Deus, na qual o latim sempre conservou toda a beleza e vitalidade".
} 
vação, aperfeiçoar o poder de concentração, desenvolver o espírito analítico e ajudar a mente a adequar-se à calma e à ponderação. ${ }^{22}$ Aliada a tais justificativas, era amiúde encontrada uma didática extremamente austera e punitiva, que visava apenas memorização de elementos gramaticais.

Esse cenário, portanto, parece ter contribuído para que textos com conteúdo obsceno, tal qual o poema 16, fossem expurgados da obra catuliana. E, como vimos observando, pode ter influenciado também em algumas propostas de tradução para o referido poema, uma vez que não caberia o uso de um poema obsceno para alguma das atividades mencionadas anteriormente. ${ }^{23}$

Das traduções publicadas em Portugal, recentemente, uma parece ter buscado transmitir ao público leitor uma tradução bastante próxima ao original latino. Trata-se da edição dos estudiosos José Pedro Moreira e André Simões, publicada pela editora Cotovia, no ano de 2012:

$\mathrm{O}$ cu e a boca vos foderei eu, Aurélio, minha bicha, Fúrio, meu paneleiro, que pelos meus versinhos me julgais pouco virtuoso, por tão delicadinhos serem. É que casto deve ser o bom poeta, não têm de o ser os seus versinhos, que além do mais têm picante e graça, sendo tão delicadinhos e pouco virtuosos, e porque podem provocar comichões, não digo aos miúdos, mas a estes peludos que não conseguem mexer as duras piças.

\footnotetext{
${ }^{22}$ Essa enumeração pode ser encontrada no texto introdutório da gramática de Almeida (1958 apud MIOTTI, 2004).

${ }^{23}$ As traduções do poema 16 para o espanhol também sofreram intervenções no sentido de silenciar a obscenidade do texto. De acordo com López-Muñoz (2014, p. 593 n. 2), tais intervenções estão presentes sobretudo nas publicações anteriores a 1975. Nesse caso, o estudioso acredita que tais censuras seriam decorrentes do regime político que vigorava na Espanha até essa data. No caso das traduções portuguesas, sabemos que durante o século XIX o país passou por regimes autoritários, o que poderia ter influenciado significativamente na regulação da linguagem empregada nas publicações.
} 
Vós, lá por "muitos milhares de beijos" terdes lido, achais que sou pouco macho? $\mathrm{O}$ cu e a boca vos foderei eu!

Ao observamos as traduções portuguesas aqui apresentadas, parece-nos possível afirmar que o poema 16 de Catulo tem, por fim, recebido o tratamento que lhe foi negado por muitas décadas. Já no Brasil, contamos atualmente com poucas traduções do poema 16, mas que procuraram informar ao leitor, seja por meio da tradução mesma, seja por meio de notas, os recursos empregados por $\mathrm{Ca}$ tulo, mantendo, sobretudo, o vocabulário obsceno aproximado ao utilizado pelo poeta veronense.

A primeira tradução a que tivemos acesso é a de Paulo Sérgio de Vasconcellos, publicada no ano de 1991 pela editora Hucitec. Nessa edição, que apresenta tradução e análise dos poemas dedicados a Lésbia, a tradução do poema 16 encontra-se no estudo introdutório acerca da poética de Catulo. À tradução, segue uma explicação sobre esse poema capital para os estudos poéticos. A seguir, observemos a tradução proposta por Vasconcellos:

Eu comerei vocês e farei com que me chupem, Aurélio veado e bicha Fúrio,

Que, a partir dos meus versinhos, julgaram

Que, por serem delicados, sou pouco recatado.

Ora, convém que o escrupuloso poeta seja casto

Ele próprio, quanto a seus versinhos, não é nem um pouco necessário,

Já que só têm, justamente, sal e graça

Se são delicados e pouco recatados

E podem excitar o tesão

Não digo dos meninos, mas desses peludos

Que não conseguem mover os lombos endurecidos.

Vocês, que muitos milhares de beijos

Leram, julgam que eu não sou lá muito homem?

Eu comerei vocês e farei com que me chupem. 
Uma nova proposta de tradução foi publicada por Vasconcellos, no ano de 2003. Em versos metrificados, a tradução se encontra no décimo quarto volume da revista Modelo 19, em um artigo acerca da intertextualidade entre os poemas 5 e 16 de Catulo: ${ }^{24}$

\author{
Enrabarei vocês, farei que chupem, \\ Aurélio passivona e bicha Fúrio, \\ Que a mim, por meus versinhos só, julgaram, \\ Como são delicados, não pudico. \\ Pois casto deve ser o pio poeta \\ Ele próprio, os versinhos não é preciso, \\ Já que têm justamente sal e graça \\ Se delicados são e não pudicos \\ E podem incitar algum tesão \\ Não digo nos meninos: nos peludos \\ Que não podem mover os duros lombos. \\ Vocês, que muitos mil de beijos leram, \\ Que eu não sou muito macho estão julgando? \\ Enrabarei vocês, farei que chupem.
}

Como acima observado, por meio dessas traduções o leitor parece conseguir construir um sentido para o texto muito próximo ao sentido do texto latino de Catulo, diferentemente do que ocorre nas traduções anteriores, em que essa construção é impedida, seja pela ausência dos versos, seja pela sublimação nas propostas dos tradutores. Em se tratando de um poema tão censurado ao longo do tempo, a preocupação de um tradutor que visa não somente traduzir o poema, mas também informar ao seu leitor o contexto em que o poema foi produzido, sobretudo se pensarmos no distanciamento temporal dessas duas sociedades, parece conferir a Catulo o reconhecimento que esteve ausente em diversas outras traduções.

${ }^{24}$ Essa tradução também se encontra em Vasconcellos (2012a, p. 176); (2012b, p. 89-90); (2016, p. 54-55).

Cad. Trad., Florianópolis, v. 38, $\mathbf{n}^{0}$ 2, p. 120-142, mai-ago, 2018 
Procedimento semelhante também parece ter sido empregado por João Ângelo Oliva Neto, que publicou, em 1996, pela editora Edusp, a tradução poética completa da obra de Catulo. A tradução do poema, que apresentamos no início do presente trabalho, busca empregar um vocabulário que transmita, com maior proximidade possível, o sentido do texto latino. Além disso, à tradução precede um extenso e detalhado estudo sobre a poética de Catulo, a fim de que seu leitor possa se familiarizar com poesia "helenística-calimaquiana", como afirma o estudioso (OLIVA NETO, 1996, p. 12). Todos os poemas, ainda, receberam notas explicativas acerca dos recursos empregados por Catulo, atividade muito presente em textos acadêmicos sobre os estudos clássicos.

Por fim, vale mencionar que mais uma tradução do poema 16 de Catulo está prestes a ser publicada. Trata-se da versão do prof. Dr. Robson Tadeu Cesila, em versos decassílabos, que integrará a coleção Bibliotheca Latina da editora da Unicamp. ${ }^{25}$ Nessa proposta, observamos novamente que os versos obscenos em português procuram se aproximar ao sentido do texto latino:

Vou comer vosso cu e meter na boca, Aurélio viadão e Fúrio bicha, que a mim pouco pudico me julgastes por serem meus versinhos delicado.

Pois ao próprio poeta pio ser casto convém, mas seus versinhos não precisam, eles que só contêm o sal e a graça se são delicadinhos, não pudicos, e se a libido podem provocar, não digo a dos garotos, mas a desses peludos rígidos, de costas duras.

E vós, que muitos beijos mil, milhares, já lestes, me julgais não ser bem macho? Vou comer vosso cu e meter na boca.

${ }^{25}$ Agradecemos ao prof. Dr. Robson Tadeu Cesila por ceder sua tradução para integrar o presente estudo. A publicação estará presente em sua obra Epigrama: Catulo e Marcial, sexto volume da coleção Bibliotheca Latina. 
Embora nosso foco no presente estudo tenha sido a tradução do poema para a língua portuguesa, parece-nos interessante comentar que alguns tradutores para a língua inglesa também recorreram a diversos artifícios em suas publicações a fim de suavizar o conteúdo obsceno do poema. Para mencionar alguns exemplos, ao primeiro verso do poema 16, que na tradução de Oliva Neto é "Meu pau no cu, na boca, eu vou meter-vos", na tradução de F. A. Wright's, de 1926, encontramos "I'll show you I'm a man". Jack Lindsay, no ano de 1948, optou por "Aurelius down, you'll knuckle under!/ Furius up! Admit your blunder!”. Ainda que o primeiro e último versos do poema sejam idênticos, Horace Gregory, em sua edição de 1956, apresenta duas traduções distintas para os versos: "Furius, Aurelius, I'll work your/ own perversions on you and your persons" e "Come at me, and I'll be ready/ to defile you and seduce you", para os versos 1 e 14, respectivamente. Por fim, em 1956, Roy Arthur Swanson ainda segue a mesma tendência de suavizar o sentido do verso em inglês, e propõe: "I'll snag you and gag you" (WINTER, 1976, p. 257-258).

\section{Considerações finais}

Atentar para o modo como a poesia de Catulo foi recepcionada ao longo dos anos, em especial o poema 16, revela muito sobre como determinados valores morais influenciaram e comprometeram a difusão do texto latino, e, consequentemente, suas propostas de tradução. Constatamos que o poema 16 sofreu diversas formas de censura: se nas edições latinas ora o texto era expurgado, ora sofria intervenções, em outras ocasiões era desacreditado simplesmente como construto de Catulo. Nas traduções em língua portuguesa, por sua vez, seguiram-se semelhantes procedimentos.

Apresentar a um leitor de língua portuguesa versos em latim se configura, a nosso ver, um modo de censura em que o tradutor se nega a aceitar o material com o qual está lidando. De maneira semelhante, apresentar uma tradução atenuada, sem disponibilizar 
recursos para que seu leitor consiga perceber e identificar as escolhas propostas pelo tradutor, parece-nos também indicar determinada censura. Além disso, vimos também que o ensino de latim esteve por muito tempo submetido a ideais conservadores ligados à moral e à disciplina, fato que pode ter contribuído consideravelmente para a censura do poema 16.

Assim, em lugar de se tentar compreender a poesia de Catulo, parece-nos que certa parte da crítica buscou silenciar determinada característica lasciva do poeta veronense, a fim de construir a imagem de um poeta pudico. ${ }^{26}$ Ainda que cada texto traduzido seja autêntico e tenha sua autonomia, não é possível ignorar que há um vínculo entre original e tradução que, nesse caso, acaba por se perder. Entretanto, observamos que a crítica moderna tem reconhecido em Catulo a relevância da obscenidade em seus poemas.

Tal reconhecimento nos parece ser fruto da propagação dos estudos que procuram examinar o texto dissociado de seu autor empírico, sobretudo no que se refere à dessacralização dessa figura enaltecida principalmente após o Renascimento e que, por muito tempo, foi utilizada para justificar intervenções nas obras. Desse modo, hoje o leitor em língua portuguesa se depara com traduções que procuram construir um sentido em que não há esse julgamento de valor, e que procuram respeitar os elementos dos textos que destacam os recursos empregados por Catulo como parte importante da (meta)poesia catuliana em um poema tão célebre para os estudos clássicos como o carmen 16.

${ }^{26}$ Parece-nos interessante pesquisar, num segundo momento, em que medida a era vitoriana pode também ter influenciado essa abordagem da crítica de Catulo. 


\section{Referências}

ADAMS, J. N. The Latin Sexual Vocabulary. London: Duckworth, 1982.

ALVES, D. M. Os Poetas Novos em Catulo: primeiras reflexões. Língua, literatura e ensino, v. 4, p. 24-35, 2009.

. POLASTRI., B. E.; FAUSTINO, R.; LIMA, D. C.; MORAES, C. P. F. Catulo: uma nota introdutória. Língua, literatura e ensino, v. 3, p. 451-459, 2008.

CALLIMACHUS. Hymns and epigrams. With an English translation by A. W. Mair; G. R. Mair. Cambridge; London: Harvard University Press; Harvard University Press, 1989.

CATULLUS. Catullus: A commentary by C. J. Fordyce. Reprinted with corrections. Oxford: Oxford University Press, 1987.

. Catullus. Edited with a textual and interpretative commentary by D. F. S. Thomson. Toronto; Bufalo: University of Toronto Press, 1997.

CATULO. O Cancioneiro de Lésbia. Introdução, tradução e notas de Paulo Sérgio de Vasconcellos. São Paulo: Editora Hucitec, 1991.

. O livro de Catulo. Tradução, introdução e notas de João Ângelo Oliva Neto. São Paulo: Edusp, 1996.

. Carmina. Tradução de José Pedro Moreira e André Simões. Lisboa: Cotovia, 2012.

. Poesias. Tradução de Agostinho da Silva. Coimbra: Imprensa da Universidade, 1933. Disponível em: < http://www.agostinhodasilva.pt >. Acesso em: 13 out. 2016.

FITZGERALD, W. Catullan Provocations: Lyric Poetry and the Drama of Position. Berkeley: University of California Press, 1995. 
GALlARDO, M. D. La Revolución de los «Poetae Noui ». Estudios Clásicos, n. 97, p. 19-30, 1990.

KENNEY, E. J.; CLAUSEN, W. V. (Ed.). The Cambridge History of Classical Literature. Cambridge: Cambridge University Press, 1996. v. 2.

LATEINER, D. Obscenity in Catullus. In: GAISSER, J. H. (Ed.). Catullus. Oxford: Oxford University Press, 2007. p. 261-281.

LEE, T. F. Catullan Obscenity and Modern English Translation. Arts \& Sciences Electronic Theses and Dissertations. Paper 703. Disponível em: < http://opensch olarship.wustl.edu/art_sci_etds/703/ > . Acesso em: 16 ago. 2016.

LÓPEZ-MUÑOZ, M. Una nota sobre las traducciones modernas de Catulo 16. Manipulus studiorum (En recuerdo de la profesora Ana María Aldama Roy), p. 589-598, 2014.

MAgUeiJo, C.; CARVAlHO, J. L.; CAMPOS, J. A. Antologia de Poesia Latina Erótica e Satírica. Seleção, tradução e notas de Custódio Magueijo, J. Lourenço de Carvalho e J. António Campos. Lisboa: Fernando Ribeiro de Mello; Edições Afrodite, 1975.

MIOTTI, C. M. Universidades estaduais paulistas: o latim na berlinda. In: Círculo de Estudos Linguísticos do Sul - Celsul, 6, 2004, Florianópolis. Anais... Florianópolis, 2004. Disponível em: <http://www.leffa.pro.br/tela4/Textos/ Textos/Anais/CELSUL_VI > . Acesso em: 14 nov. 2016.

ROBERTS, D. Translation and the "Surreptitious Classic": Obscenity and Translatability. In: LIANERI, Alexandra; ZAJKO, Vanda (Ed.). Translation and the Classic: Identity as Change in the History of Culture. Oxford: Oxford University Press, p. 278-313, 2008.

SENA, J. Poesia de 26 Séculos. Tradução, prefácio e notas de Jorge de Sena. Porto: Editorial Inova, 1971. v. 1.

. Poesia de 26 Séculos: de Arquíloco a Nietzsche. Tradução, prefácio e notas de Jorge de Sena. Coimbra: Fora do Texto, 1993. 
TRIMBLE, G. Catullus and "comment in English": the tradition of the expurgated commentary before Fordyce. In: STRAY, S. C. (Ed.). Expurgating the Classics: Editing Out in Greek and Latin. London: Bristol Classical Press, 2012, p. 143162.

VASCONCELLOS, P. S. Persona poética e autor empírico na poesia amorosa romana. São Paulo: Unifesp, 2016.

. Milia multa basiorum once more: a proposal for an intratextual reading. Hermes, Zeitschrift für Klassische Philologie, v. 143, p. 57, 2015.

. Poesia amorosa e infâmia: eu poético e autor empírico na Roma Antiga. In: LEITE, Leni Ribeiro; SILVA, Gilvan Ventura da; CARVALHO, Raimundo (Orgs.). Gênero, religião e poder na antiguidade: contribuições interdisciplinares. Vitória: GM Editora, 2012a, p. 168-186. 105, 2012b.

A recepção da poesia amorosa na antiga Roma. Calíope, v. 24, p. 86. A construção da imagem do professor de latim no cinema. Calíope, v. 17, p. 95-115, 2007.

. Carmina 5 e 16 - Catulo. Revista de Tradução Modelo 19, v. 14, p. 67-69, 2003.

WINTER, T. N. Catullus Purified: A Brief History of Carmen 16. Arethusa, n. 6, p. 257-65, 1973.

Recebido em: 18 de novembro de 2017 Aceito em: 07 de fevereiro de 2018 Publicado em: maio de 2018

Diogo Martins Alves. E-mail: diogo.letras@gmail.com 